\title{
Reduced Heat Exposure by Limiting Global Warming to $1.5^{\circ} \mathrm{C}$
}

\author{
Andrew D. King*, Markus G. Donat, Sophie C. Lewis, Benjamin J. Henley, Daniel M.
} Mitchell, Peter Stott, Erich M. Fischer, David J. Karoly

The benefits of limiting global warming to the lower Paris Agreement target of $1.5^{\circ} \mathrm{C}$ are substantial with respect to population exposure to heat, and should impel countries to strive towards greater emissions reductions.

Since the Paris Agreement was reached in December 2015 there has been a drive in the scientific community to understand the impacts of global warming at the target levels of $1.5^{\circ} \mathrm{C}$ and $2^{\circ} \mathrm{C}^{1-3}$. A Special Report on the pathways to limiting global warming to $1.5^{\circ} \mathrm{C}$, and associated implications of this target, is being prepared by the Intergovernmental Panel on Climate Change (IPCC).

Research to date has focussed on changes in different types of climate extremes globally ${ }^{1,3}$ or regionally ${ }^{2,4}$, developing and utilising model experiments to infer differences between the two warming targets ${ }^{5}$, or the emissions and warming trajectories associated with meeting or breaching the $1.5^{\circ} \mathrm{C}$ target $t^{6,7}$. Here we approach the question of how different a $1.5^{\circ} \mathrm{C}$ world and a $2^{\circ} \mathrm{C}$ world are through the lens of human population exposure to historically unprecedented heat extremes, warmer than those observed since 1950, in Europe. We show that the population levels exposed to hot summers above the current record increase dramatically from $1.5^{\circ} \mathrm{C}$ to $2^{\circ} \mathrm{C}$. In the past, record summer heat in Europe has been associated with severe heatwaves resulting in thousands of excess deaths ${ }^{8}$, albeit with high variability in impacts between events, in part due to non-climatic factors. Nonetheless, global warming must be limited to reduce human exposure to historically unprecedented heat.

\section{Warming summers}


24 People tend to remember record hot summers ${ }^{9}$, and such extremes are well-observed over a

25 long period in Europe especially, so they provide a useful benchmark for investigating future

26 climate extremes. The warmest observed summers (June-August) in Europe from 1950-2017

27 are associated with average temperatures below $15^{\circ} \mathrm{C}$ in parts of Scandinavia, Scotland and

28 the Alps, rising to temperatures exceeding $25^{\circ} \mathrm{C}$ around much of the Mediterranean (Figure

29 1a). Since populations and ecosystems are well-acclimatised to temperature variability in

30 their home locations, summer temperatures exceeding these observed records could have dire

31 consequences even where they may be relatively low in northern Europe compared to Spain

32 and Italy, for example ${ }^{10}$.

33 Over the majority of Europe, the hottest summers on record (since 1950) occurred after 2000

34 (Figure 1b) with the summers of 2003 and 2006 being the hottest over much of western

35 Europe ${ }^{11,12}$ while 2010 was the hottest further east. However, there are exceptions, for

36 example, in Central England the hottest summer remains 1976. All the aforementioned

37 summers were associated with shorter spells of record-breaking extreme temperatures and

38 major impacts, such as excess heat-related deaths in western Europe in $2003^{8}$, wildfires in

39 Russia in 2010, and severe drought in England in 1976.

40 In future $1.5^{\circ} \mathrm{C}$ and $2^{\circ} \mathrm{C}$ worlds, represented in bias-adjusted model projections, we find an

41 increase in the likelihood of historically unprecedented hot summers (hereafter used to refer

42 to summer-average temperatures exceeding the observed record summer during 1950-2017 at

43 each location). The probability of a hot summer exceeding the current record is higher across

44 Europe in a $2^{\circ} \mathrm{C}$ world than in a $1.5^{\circ} \mathrm{C}$ world, and at least doubles in parts of southern and

45 eastern Europe (Figure 2a). This illustrates the benefit of limited global warming through

46 reduced heat extremes ${ }^{4,13}$.

\section{Increasing population exposure to summer heat}


48 In each year within each world ("natural", "current", " $1.5^{\circ} \mathrm{C}$ " and " $2{ }^{\circ} \mathrm{C}$ ") 2,4 we aggregate the population (based on 2010 estimates; see Supplementary Information S4) experiencing extreme high summer-average temperature anomalies, temperatures that are unprecedented in

51 the observed record. Figure $2 \mathrm{~b}$ shows probability distributions of aggregated population totals

52 in Europe exposed to these hot summers in each world. In the current climate most summers

53 see a small proportion of Europe's overall population exposed to temperatures above the

54 observed record with a median estimate of 45 million (in recent observations, 2003 was an exceptional year when larger numbers of people experienced a new record). The population exposed to summer heat rises for the simulated Paris Agreement target worlds. On average, in the simulated $1.5^{\circ} \mathrm{C}$ world, 90 million people (or $11 \%$ of the estimated 2010 population of the continent) are exposed to hot summers beyond the observed record (i.e. half of summers would have more than 90 million people exposed to historically unprecedented summeraverage temperatures). In the simulated $2^{\circ} \mathrm{C}$ world, on average there are 163 million Europeans (or $20 \%$ of the continent's population) experiencing summer temperatures exceeding the observed 1950-2017 record. That is equivalent to more than ten times the metropolitan population of Western Europe's largest city, London, and is about twice the population of Germany.

Population exposure to historically unprecedented summer heat increases dramatically even at the relatively low global warming levels of the Paris Agreement (Figure 2c). For example, the chance of having a summer with such widespread heat that at least 400 million people (or almost $50 \%$ of the continental population) experience a summer temperature exceeding the historical record is negligible in the current climate. In contrast, in the modelled $1.5^{\circ} \mathrm{C}$ world such an event would occur on average in one-in-18 years (Figure $2 \mathrm{c}$ ) and in the $2{ }^{\circ} \mathrm{C}$ world

71 simulations the likelihood rises such that a high exposure event would occur on average once 72 every seven years (Figure 2c). We have already raised the odds in favour of hotter summers 
and increased population exposure to summer heat, and even under low global warming scenarios associated with the Paris Agreement this effect is exacerbated.

\section{An incentive to strive for a low global warming scenario}

As the Earth warms populations will have to cope with more frequent and intense heat extremes $^{1,3}$. We show that for the densely-populated region of Europe which has previously experienced devastating impacts of severe heat, particularly in $2003^{8,14}$ and $2010^{11}$, there is a substantial benefit, with respect to reduced heat exposure, to limiting global warming to the $1.5^{\circ} \mathrm{C}$ Paris target. This benefit is perceptible even when compared with a $2^{\circ} \mathrm{C}$ world, let alone higher levels of global warming. This benefit is also likely to extend to other regions of the world ${ }^{15}$, although we chose to focus only on the European continent (see Supplementary Information S1, S10 for further discussion).

Prior to the Paris Agreement more focus had been placed on $2^{\circ} \mathrm{C}$ and higher levels of global warming. Only since the end of 2015 has there been a shift in focus in the scientific community towards investigating the implications of lower levels of global warming. While it is recognised that it will be very difficult to meet the aspirational $1.5^{\circ} \mathrm{C}$ Paris target, the benefits from doing so would be very large with respect to limiting the frequency and intensity of hot extremes and the consequences of these events. This may act as additional motivation for the world to aim for the $1.5^{\circ} \mathrm{C}$ Paris target and develop an emissions pathway and associated technologies that will increase the likelihood of achieving the target.

European countries are among the most ambitious in the world in tackling climate change through with strong intended reductions in greenhouse gas emissions. Here we illustrate that this need not be a selfless act; the countries and peoples of Europe, especially the Mediterranean region which has suffered in recent hot summers, would benefit from a future of relatively fewer hot summers with limited global warming. 
97 Regardless of the emissions path the world takes over the next few years, global warming will continue, and heat extremes and associated population exposure will increase. In addition to efforts to limit global warming, strategies to adapt to hotter summers, outside of the observed range we have experienced to date, will be needed to reduce heat-health impacts.

Andrew D. King, Benjamin J. Henley, and David J. Karoly are at the ARC Centre of

Excellence for Climate System Science, School of Earth Sciences, University of Melbourne, Melbourne, 3010, Australia.

Markus G. Donat is at the ARC Centre of Excellence for Climate System Science, Climate

Change Research Centre, University of New South Wales, Sydney, 2052, Australia.

Sophie C. Lewis was at the Fenner School of Environment and Society, Australian National

University, Canberra, 2601, Australia and is now at the School of Physical Environmental

and Mathematical Sciences, University of New South Wales, Canberra, 2612, Australia.

Daniel M. Mitchell is at the School of Geographical Sciences, University of Bristol, Bristol, 110 BS8 1SS, UK.

Peter Stott is at the Met Office Hadley Centre, Exeter, EX1 3PB, UK and the College of $U K$.

114 Erich M. Fischer is at the Institute for Atmospheric and Climate Science, ETH Zurich, 115 Zurich, 8092, Switzerland.

*e-mail: andrew.king@unimelb.edu.au

\section{References}

118 1. Schleussner, C.-F. et al. Differential climate impacts for policy-relevant limits to global warming: the case of 1.5 \&amp;deg;C and 2 \&amp;deg;C. Earth Syst. Dyn. 7, 
2. King, A. D., Karoly, D. J. \& Henley, B. J. Australian climate extremes at $1.5^{\circ} \mathrm{C}$ and $2{ }^{\circ} \mathrm{C}$ of global warming. Nat. Clim. Chang. 7, 412-416 (2017).

3. Perkins-Kirkpatrick, S. E. \& Gibson, P. B. Changes in regional heatwave characteristics as a function of increasing global temperature. Sci. Rep. 7, 12256 (2017)

4. King, A. D. \& Karoly, D. Climate extremes in Europe at 1.5 and 2 degrees of global warming. Environ. Res. Lett. (2017). doi:10.1088/1748-9326/aa8e2c

5. Sanderson, B. M. et al. Community Climate Simulations to assess avoided impacts in $1.5^{\circ} \mathrm{C}$ and $2{ }^{\circ} \mathrm{C}$ futures. Earth Syst. Dyn. Discuss. (2017). doi:10.5194/esd-2017-42

6. Millar, R. J. et al. Emission budgets and pathways consistent with limiting warming to $1.5^{\circ}$ C. Nat. Geosci. 10, 741-747 (2017).

7. Henley, B. J. \& King, A. D. Trajectories toward the $1.5^{\circ} \mathrm{C}$ Paris target: Modulation by the Interdecadal Pacific Oscillation. Geophys. Res. Lett. 44, 4256-4262 (2017).

8. Mitchell, D. et al. Attributing human mortality during extreme heat waves to anthropogenic climate change. Environ. Res. Lett. 11, 74006 (2016).

9. Hansen, J., Sato, M. \& Ruedy, R. Perception of climate change. Proc. Natl. Acad. Sci. 109, E2415-E2423 (2012).

10. Gasparrini, A. et al. Mortality risk attributable to high and low ambient temperature: a multicountry observational study. Lancet (London, England) 386, 369-75 (2015).

11. Barriopedro, D., Fischer, E. M., Luterbacher, J., Trigo, R. M. \& García-Herrera, R. The hot summer of 2010: redrawing the temperature record map of Europe. Science 
12. Russo, S., Sillmann, J. \& Fischer, E. M. Top ten European heatwaves since 1950 and their occurrence in the coming decades. Environ. Res. Lett. 10, 124003 (2015).

13. Ciavarella, A., Stott, P. \& Lowe, J. Early benefits of mitigation in risk of regional climate extremes. Nat. Clim. Chang. 7, 326-330 (2017).

14. Stott, P. A., Stone, D. A. \& Allen, M. R. Human contribution to the European heatwave of 2003. Nature 432, 610-614 (2004).

15. Lehner, F., Deser, C. \& Sanderson, B. M. Future risk of record-breaking summer temperatures and its mitigation. Clim. Change 146, 363-375 (2018).

151

152 153

154

155

156

157

\section{Acknowledgements}

Several authors received funding from the Australian Research Council including A.D.K. and D.J.K (CE110001028), M.G.D. (DE150100456), S.C.L. (DE160100092) and B.J.H. (LP150100062). We acknowledge the support of the NCI facility in Australia and the World Climate Research Programme's Working Group on Coupled Modelling, which is responsible for CMIP, and we thank the climate modelling groups for producing and making available their model output. For CMIP the US Department of Energy's Program for Climate Model Diagnosis and Intercomparison provides coordinating support and led development of software infrastructure in partnership with the Global Organization for Earth System Science Portals. We acknowledge the E-OBS data set from the EU-FP6 project ENSEMBLES (http://ensembles-eu.metoffice.com) and the data providers in the ECA\&D project (www.ecad.eu).

\section{Author contributions}


A.D.K. had the idea for the study. A.D.K. and M.G.D. developed the methodology. A.D.K. performed the analysis and led the writing of the paper. All authors contributed to the writing of the paper.

\section{Additional information}

Supplementary information is available in the online version of the paper.

Figure 1: Across most of Europe the warmest summers occurred in 2003, 2006 or 2010.

Maps showing a) the highest average summer temperatures and b) the decade in which the warmest summer occurred. (See Supplementary Information S1, S2 for details.)

Figure 2: There is a much greater likelihood of, and population exposure to, historically unprecedented warm summers at $2^{\circ} \mathrm{C}$ of global warming than $1.5^{\circ} \mathrm{C}$. a) best estimate ratio of hot summers exceeding the observed record between a $2^{\circ} \mathrm{C}$ world and a $1.5^{\circ} \mathrm{C}$ world. b) the probability of European population numbers exposed to historically unprecedented hot summers for a given year in the current world, a $1.5^{\circ} \mathrm{C}$ world and a $2{ }^{\circ} \mathrm{C}$ world. c) likelihoods of population exposure to historically unprecedented hot summers exceeding different thresholds. Best estimates are shown in bold with $90 \%$ confidence intervals in parentheses. (See Supplementary Information S3-S5 for details.) 


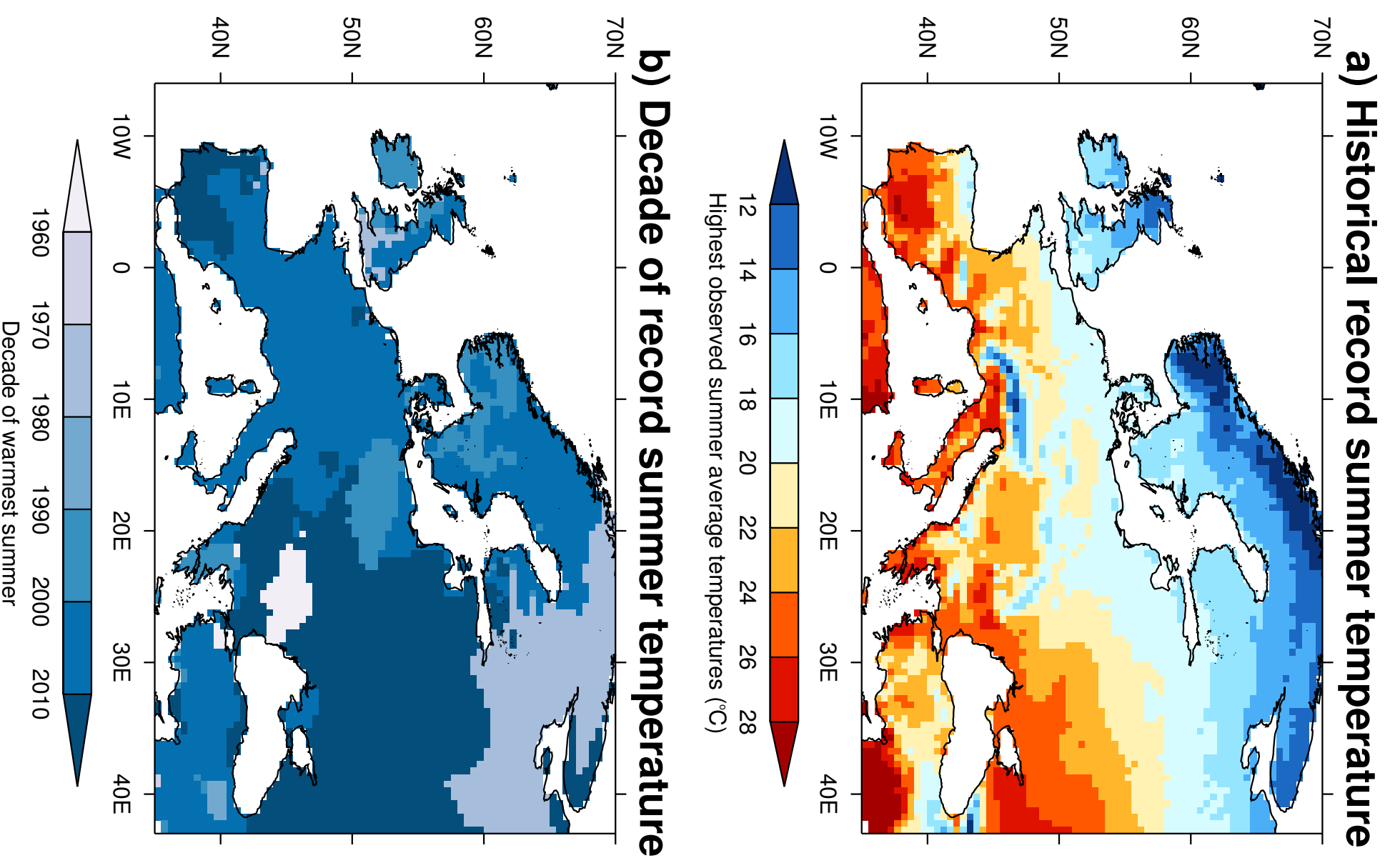


a) Ratio of unprecedented hot summers $\left(2^{\circ} \mathrm{C}\right.$ vs. $\left.1.5^{\circ} \mathrm{C}\right)$

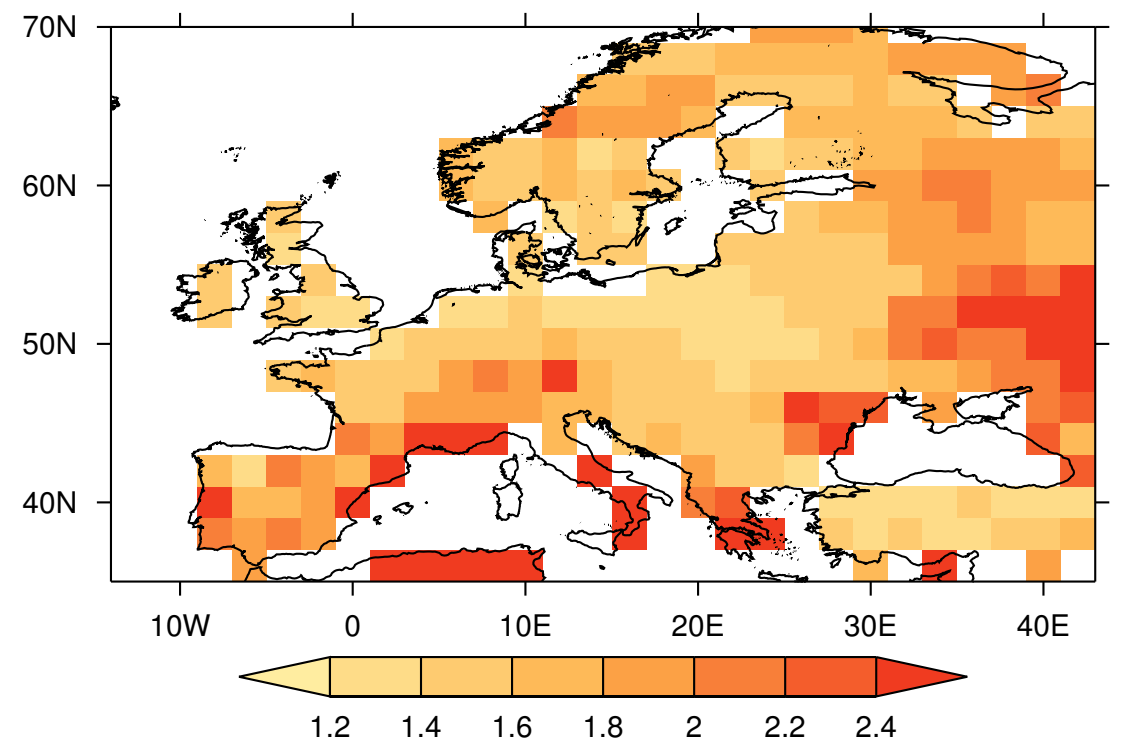

Ratio of unprecedented hot summers in $2^{\circ} \mathrm{C}$ world vs. $1.5^{\circ} \mathrm{C}$ world

b) Population exposure to unprecedented hot summers

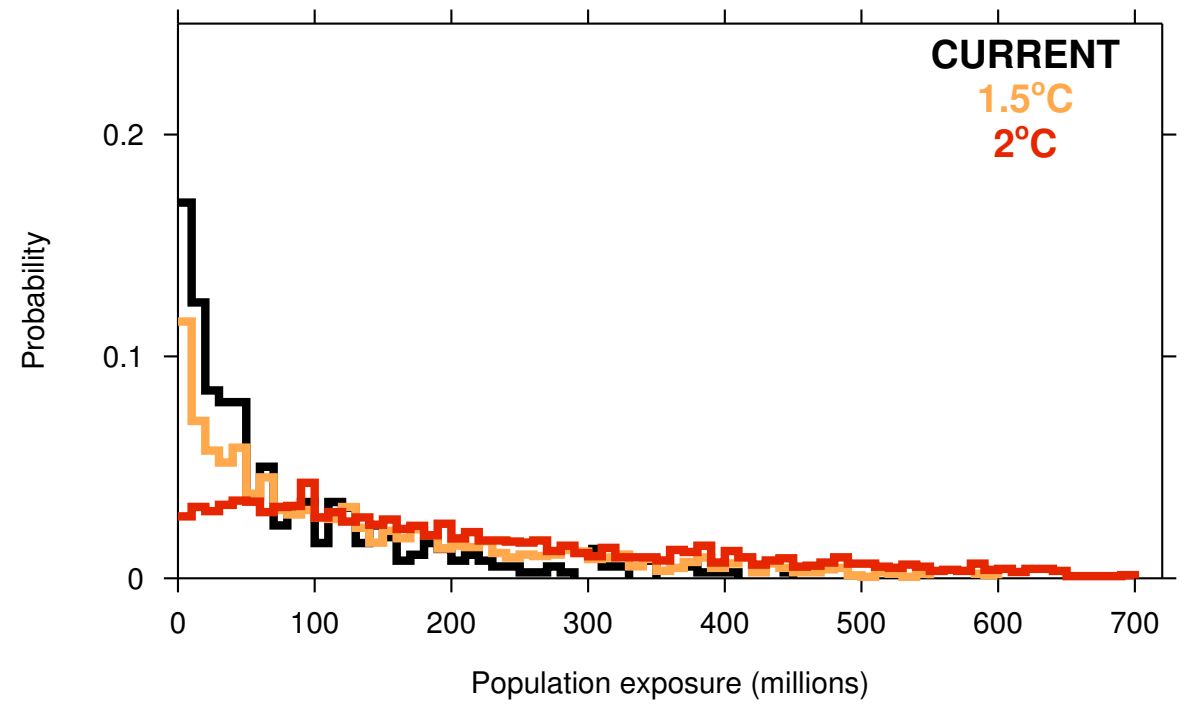

c) Chance of high population exposure event per year

\begin{tabular}{|c|c|c|c|c|}
\hline POPULATION & NAT & CURRENT & $1.5^{\circ} \mathrm{C}$ & $2^{\circ} \mathrm{C}$ \\
\hline > 100 million & $\begin{array}{l}11 \% \\
(0-33 \%)\end{array}$ & $\begin{array}{c}29 \% \\
(16-47 \%)\end{array}$ & $\begin{array}{c}\mathbf{4 7} \% \\
(21-78 \%)\end{array}$ & $\begin{array}{c}67 \% \\
(46-98 \%)\end{array}$ \\
\hline$>200$ million & $\begin{array}{c}6 \% \\
(0-29 \%)\end{array}$ & $\begin{array}{l}10 \% \\
(1-21 \%)\end{array}$ & $\begin{array}{l}25 \% \\
(7-50 \%)\end{array}$ & $\begin{array}{c}\mathbf{4 2} \% \\
(19-83 \%)\end{array}$ \\
\hline$>300$ million & $\begin{array}{l}0 \% \\
(0-0 \%)\end{array}$ & $\begin{array}{c}5 \% \\
(0-12 \%)\end{array}$ & $\begin{array}{l}13 \% \\
(2-30 \%)\end{array}$ & $\begin{array}{l}26 \% \\
(8-62 \%)\end{array}$ \\
\hline$>400$ million & $\begin{array}{l}0 \% \\
(0-0 \%)\end{array}$ & $\begin{array}{l}1 \% \\
(0-2 \%)\end{array}$ & $\begin{array}{c}6 \% \\
(0-15 \%)\end{array}$ & $\begin{array}{l}15 \% \\
(3-39 \%)\end{array}$ \\
\hline
\end{tabular}

